MEDAR

26,3

\section{Guest editorial}

\section{Intellectual capital and Big Data: a managerial revolution or a reality?}

\section{4}

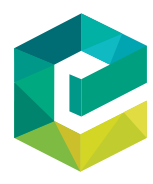

Meditari Accountancy Research Vol. 26 No. 3,2018 pp. $354-360$

(C) Emerald Publishing Limited 2049-372X

DOI 10.1108/MEDAR-08-2018-345

\section{Introduction}

In the call for papers, we outlined that the objective of this special issue is to explore emerging trends in intellectual capital (IC) accounting research in light of the rise of Big Data (McAfee and Brynjolfsson, 2012). In 2001, Laney characterised Big Data with "three Vs" - volume, velocity and variety. Since then, scholars and researchers in the field of information management have added veracity, variability and, most importantly, value as further elements of this profound phenomenon (Gandomi and Haider, 2015). Thus, taking advantage of Big Data is becoming more compelling than ever before. The need for accountants and managers to understand how to translate Big Data into an organisation's current and future value in the form of IC is both great and pressing (Secundo et al., 2017).

Big Data can contribute to more transparent management of relational capital, more responsive control of human capital and more timely decision-making for structural capital (Erickson and Rothberg, 2015; Manyika et al., 2011). Explicitly recognising the importance of Big Data is a fruitful way to analyse IC management praxis and how the IC inside an organisation is connected to the IC outside an organisation and beyond, into society. However, how do the potential benefits fit within the IC universe? From an IC perspective, which trends relate to Big Data, business intelligence and business analytics and the cloud? Are organisations still finding value in basic data and information? How does Big Data change the way we conceptualise IC and, moreover, how we value it?

This special issue intends to answer these questions and to reflect on the state of IC and Big Data research. Our goal is to make the benefits of Big Data evident for those in the field of IC management and to understand the dynamics of, and opportunities within, the value creation process. In developing the call for papers, we drew inspiration from the research agenda on IC and Big Data developed by Secundo et al. (2017). We used the dimensions of who, how, why and what to present a portfolio of state-of-the-art thinking at this nexus for contemplation and for future investigation. Accordingly, some topics have been identified as emerging areas for deeper understanding, while others have been chosen for their impacts and perspectives on Big Data in IC management and the way they help transform Big Data into IC to create value for an organisation.

We encouraged submissions that explored methodologies, technologies and processes. We wanted to open up the black box of "data enabled organisations" (Baumgarten and Dickstein, 2013, p. 1), where Big Data practices are being used to explore innovative challenges in IC management. In response, we received many submissions with original contributions to theory and many with empirical perspectives on how to harness the power of Big Data for IC.

\section{Structure of the special issue}

This special issue has been arranged in logical order that takes readers from literature reviews exploring the state-of-the-art in leading-edge papers through to novel theoretical investigative frameworks, metrics and critical dimensions, and finally to empirical investigations in different contexts.

The state-of-the-art. The first part comprises four articles describing the state-of-theart literature in fourth-stage IC research (Dumay and Garanina, 2013). These papers 
provide a context for understanding Big Data's role as a new form of value and as a relevant input supporting the dichotomy of IC inside and outside the organisation (De Santis and Presti, 2018). Botes et al. (2018) set Big Data as the stage for a new IC asset and a source of renewed interest in accounting for IC, while Harlow (2018) takes us further into the emerging fifth stage of IC (Dumay et al., 2018) based on artificial intelligence and analytics. In highlighting how IC can be developed as a strategic and sustainable goal for firms, Harlow (2018) connects those goals with IC outcomes. A cross-disciplinary overview of how Big Data contributes to the value creation process ends this section (Uden and Del Vecchio, 2018). This synthesis of IC in a service ecosystem explores how multiple stakeholders engage.

"The relationship between intellectual capital and Big Data: a review", by De Santis and Presti (2018), demonstrates how the advent of Big Data has impacted the traditional dimensions of IC through a structured literature review. The magnitude and speed of risks and opportunities have been amplified to the point where traditional managerial solutions need to be revised if they are to weather the challenges of value creation from Big Data. The framework (De Santis and Presti, 2018) present is proposed as a useful decision-making tool for IC managers to practically evaluate investments in Big Data technologies.

"The fall and rise of intellectual capital accounting: new prospects from the Big Data revolution?" by Botes et al. (2018) contains conceptual and practical insights into how Big Data represents a new asset for IC. Based on a conceptual framework informed by decision science theory, the paper demonstrates how an integrated framework can support the process of creating value from Big Data. Data quality, security and privacy, data visualisation and user interaction are each examined in the context of IC management practices as elements of human and structural capital.

Focussing on a larger background that includes the literature on knowledge management strategy (KMS), Harlow's (2018) paper "Developing a knowledge management strategy for data analytics and intellectual capital" highlights the connections between strategic intent, KMS and Big Data analytics. The article presents an extended model of interrelationships, which is useful for connecting Big Data with KMS. Aimed at establishing a new research agenda based on the intersection of KMS and IC through Big Data, the paper attempts an original definition of an emerging fifth stage of IC research that relies on artificial intelligence and Big Data analytics to develop IC and strategic intent.

"Transforming the stakeholders' Big Data for intellectual capital management", authored by Uden and Del Vecchio (2018), adopts a qualitative, multidisciplinary research method based on IC management, Big Data, service science and activity theory. The paper defines a conceptual framework for transforming Big Data into organisational value, which represents a marked contribution to advancing the fourth-stage IC research agenda. The benefits of adopting a cross-disciplinary lens to investigate Big Data and value creation are juxtaposed with conventional sociological and philosophical theories to inspire a renewed perspective on IC management.

Metrics. The second section comprises two articles. Focusing on the dimensions of authority and visibility as proxy for digital relational capital, Paklina et al. (2018) defines a set of critical metrics for evaluating its impact on IC management and company performance. La Torre and Dumay (2018) explore some critical issues associated with the value creation process from a Big Data perspective. Monitoring and managing the security of data and privacy violations are essential for ensuring the integrity of a company's ecosystems. 
MEDAR

26,3
Paklina et al.'s (2018) paper, "Digital relational capital of a company", analyses eight metrics for evaluating company performance with respect to managing digital relational capital from an IC perspective. Using a two-stage fixed-effect regression, these metrics demonstrate a way to quantitatively assess Big Data's contribution to a company's relational capital for use in decision-making. This article offers a novel and valuable contribution to IC management theory and practice in the digital age.

"Breaching intellectual capital: critical reflections on Big Data security", by La Torre and Dumay (2018), examines Big Data from an IC research perspective through the lens of ecosystems. The paper unveils the practical, but not previously considered, risks of creating value from Big Data to organisations and society. The paper adopts a critical research methodology in three phases - insight, critique and transformative redefinition - to present a practical guide for managing Big Data and its cyber-threats to IC.

Intellectual capital management from a Big Data perspective in practice. The last three papers offer interesting empirical contexts in relation to the Big Data phenomenon. Each involves the process of value creation and IC management through interactions with a plurality of stakeholders, and each shows that a Big Data perspective toward IC management is not limited to particular industries. Romanelli's (2018) paper presents some interesting contextual evidence for value creation and innovative business models in museums and other organisations concerned with cultural heritage. Ndou et al. (2018) explores IC disclosure at a private university struggling to compete in a new era of competition and multidimensional decision-making. Milla et al. (2018) examines competitiveness in the context of health care with a view to core value, adding value and future-oriented production. By confirming the contribution of Big Data to more effective management of IC in all its components, the models and theoretical constraints at the base of these articles reveal opportunities for replication in different contexts and on larger scales.

"Museums creating value and developing intellectual capital by technology: from virtual environments to Big Data” provides a conceptual framework to explain how museums can sustain IC and value creation by designing virtual environments for managing Big Data (Romanelli, 2018). The paper shows how museums can use archival data, Big Data and digital technologies to increase user involvement and participation in defining cultural heritage and creating value.

"Understanding intellectual capital disclosure in online media Big Data: an exploratory case study in a university", by Ndou et al. (2018), explores how Big Data generated through online media can be used as a rich source of data for IC in a university. Their analysis of a private Albanian university's approach to Big Data through collective intelligence shows that IC is an important part of how universities operate and that social media can be used as a viable disclosure channel for communicating IC, even if unintentionally.

"The new era of business intelligence: big data's potential in the private healthcare value creation" focuses on the health-care sector. Through multiple case studies of private organisations in Finland, the paper offers empirical evidence to support data-driven decision-making and demonstrate the value and benefits of business intelligence derived from Big Data (Milla et al., 2018). The study carries several theoretical implications and many practical implications for reasoning about the forces and dynamics that characterise business strategy in this complex industry. 
Main findings and contributions. The papers published in this special issue offer original contributions that advance knowledge about IC in the age of Big Data. Each reflects state-ofthe-art research and/or related practice, and each identifies emerging issues and areas for future investigations.

Specifically, we answer several research topics from the call for papers:

- re-conceptualise IC from a Big Data perspective (Botes et al., 2018);

- explore the impact of Big Data in IC reporting and disclosure, (De Santis and Presti, 2018); Ndou et al., 2018);

- transform the Big Data generated by stakeholders and organisational ecosystems into value (Romanelli, 2018; Uden and Del Vecchio, 2018; La Torre and Dumay 2018);

- $\quad$ analyse the role of social media for creating IC (Ndou et al., 2018); and

- propose management processes and practices to foster Big Data acquisition for IC (Harlow, 2018; Paklina et al., 2018, La Torre and Dumay, 2018).

At the end of our experience as guest editors, it is important to remark on some emerging issues that should constitute the starting point for future research.

The fourth stage of IC research is intrinsically linked to the emerging phenomenon of Big Data. As all the papers in this special issue assert, the huge amounts of available data resulting from technological advancements, such as the Internet of People and the Internet of Things, often represent opportunities to create value and improve the competitiveness of an organisation. Further, the growing complexity of acquiring, managing and exploiting Big Data relies on advanced technologies and sophisticated algorithms. Yet, each of these papers presents meaningful evidence that human and relational capital remain central to the value creation process. Technology and the traditional capitals must work together to effectively create and manage IC. The methodological approaches and cross-disciplinary frameworks presented in these papers are effective ways for IC scholars and managers to explore the topics arising from the intersection of IC and Big Data. For example, De Santis and Presti (2018) present a way to evaluate the impact of Big Data technologies on IC management. Romanelli (2018) designs a data-driven innovation strategy in the context of a museum. And Milla et al. (2018) explore the benefits of adopting artificial intelligence and analytics in the healthcare sector.

The papers in this special issue are each founded in a different theoretical and methodological approach, and each finds a convergence between science and business management, IC accounting or strategic management to analyse the implications of Big Data on IC. Harlow (2018) incorporates information systems; Paklina et al. (2018) explore Web performance metrics; Ndou et al. (2018) draw on analytics and social science as a form of collective intelligence (Ndou et al., 2018); La Torre and Dumay (2018) scrutinise cybersecurity; Uden and Del Vecchio (2018) adopt activity theory, while Botes et al. (2018) integrate decision science. The range of approaches and disciplines found in these papers evidences the lively and dynamic interest in IC by a growing community of crossdisciplinary researchers and practitioners.

Future research opportunities. Despite the many innovative approaches to addressing the current challenges of IC management provided in this special issue, other questions remained unanswered, and many of these papers contain the roots of future investigations.

The contributions made by papers in the "The state-of-the-art" section need to be contextualised in a larger and differentiated range of empirical settings. For instance, 
MEDAR

26,3

\section{8}

De Santis and Presti's (2018) framework for creating value from intangible assets using Big Data technologies could be validated through case studies of different organisations. The cognitive and behavioural dynamics between data, IC information and user interactions that Botes et al. (2018) claim underpin Big Data's value for IC also contain some fruitful directions for future research. Among these are:

- exploring the potential of human and structural capital to generate trust in Big Data;

- the readiness of auditing practices to combat the security risks associated with value creation from Big Data; and

- analyses of human interactions and influence on new value creation processes.

Harlow (2018) highlights the need for further inquiry into the theory and practice of the fifth stage of IC research. To effectively develop IC, strategic intent needs to be redefined in the context of artificial intelligence and Big Data analytics. While the conceptual model presented in Harlow (2018) is a foundational contribution to the research agenda of advancing IC research into its fifth stage (Dumay et al., 2018), more work is needed. Uden and Del Vecchio (2018) call for replication of their investigative framework to transform the Big Data generated by stakeholders into IC through the lens of service science and activity theory on a larger sample of entrepreneurial universities and in different organisational contexts.

The opportunities in "Metrics" also centre on replicating and contextualising IC assessment criteria in real contexts. Paklina et al. (2018) recommend testing their ideas on digital relational capital in different national contexts and industrial settings. La Torre and Dumay (2018) identify voracity as a new dimension of the Big Data phenomenon and call for further investigation into the "new empiricism" that has resulted from an increasing demand for data-driven knowledge. As part of a wider research agenda for IC and accounting, these authors also call for more empirical research that embraces an interdisciplinary research agenda at the ecosystem level. Open questions remain about Big Data's future contributions to sustainable, transparent and equal decision-making and the detrimental implications of Big Data on IC management.

Arguably, the most numerous opportunities emerge in researching the praxis of Big Data and IC management. Romanelli (2018) suggests the need to empirically investigate how to design virtual environments and promote data-driven innovation in the context of museums. Ndou et al. (2018) examine the influence of new media on the IC disclosures of a private Albanian university, identifying the need for further evidence in other types of disclosure mediums that make IC visible on a wider scale than periodic reports. Similar to Dumay's (2016) call for more research into the importance of the opinions and sentiments shared by stakeholders through a social media, Ndou et al. (2018) also highlight the need for new research to examine the online disclosure data generated by stakeholders and stakeseekers. In Milla et al.'s (2018) case study of private health care in Finland, researchers are directed toward replicating and enlarging the base of available data to further test their model in other clinics and other contexts. Almost all authors in the special issue promote the idea of future studies to identify interdisciplinary frameworks that can define criteria or serve as business intelligence tools for creating value from Big Data in specific sectors. Finally, several questions went unanswered in the responses to this special issue. The most prescient topics include a deep exploration of Big Data's implications on IC reporting and disclosure: an examination of the processes and dynamics in stakeholder engagement from an ecosystem perspective and measuring and managing the IC drawn from Big Data for all organisations. 
We hope this special issue will inspire the future work of scholars and researchers in the field of IC and in the larger family of business management and engineering and that the ideas presented here motivate new contributions for interpretation and synthesis.

Giustina Secundo

Department of Engineering for Innovation, University of Salento, Lecce, Italy

John Dumay

Department of Accounting and Corporate Governance, Macquarie University, Ryde,

Pasquale Del Vecchio

Department of Engineering for Innovation, University of Salento, Lecce, Italy

\section{References}

Baumgarten, J. and Dickstein, M. (2013), "Beyond the hype: building a big data-enabled organization", available at: www.spencerstuart.com/research-and-insight/beyond-the-hypebuilding-a-big-data-enabled-organisation

Botes, V., La Torre, M., Dumay, J., Rea, M. and Odendaal, E. (2018), "The fall and rise of intellectual capital accounting new prospects from the big data revolution?", Meditari Accountancy Research.

De Santis, F. and Presti, C. (2018), "The relationship between intellectual capital and big data: a review", Meditari Accountancy Research.

Dumay, J. (2016), A critical reflection on the future of intellectual capital: from reporting to disclosure, Journal of Intellectual capital, Vol. 17 No. 1, pp. 168-184.

Dumay, J. and Garanina, T. (2013), "Intellectual capital research: a critical examination of the third stage", Journal of Intellectual Capital, Vol. 14 No. 1, pp. 10-25.

Dumay, J., Guthrie, J. and Rooney, J. (2018), "The critical path of intellectual capital", in Guthrie, J., Dumay, J., Ricceri, F. and Nielsen, C. (Eds), The Routledge Companion to Intellectual Capital: Frontiers of Research, Practice and Knowledge, Routledge, London, pp. 21-39.

Erickson, S. and Rothberg, H. (2015), "Big data and knowledge management: establishing a conceptual foundation", Leading Issues in Knowledge Management, Vol. 2, p. 204.

Gandomi, A. and Haider, M. (2015), "Beyond the hype: big data concepts, methods, and analytics", International Journal of Information Management, Vol. 35, pp. 137-144.

Harlow, H. (2018), "Developing a knowledge management strategy for data analytics and intellectual capital", Meditari Accountancy Research.

La Torre, M. and Dumay, J. (2018), "Breaching intellectual capital: critical reflections on big data security", Meditari Accountancy Research.

McAfee, A. and Brynjolfsson, E. (2012), "Big data: the management revolution", Harvard Business Review, October 2012, pp. 61-68.

Manyika, J., Chui, M. and Brown, B. (2011), Big Data: The next Frontier for Innovation, Competition, and Productivity, The McKinsey Global Institute, Las Vegas.

Milla, R., Myllärniemi, J. and Helander, N. (2018), "The new era of business intelligence: big data potential in the private healthcare value creation", Meditari Accountancy Research.

Ndou, V., Secundo, G., Dumay, J. and Elvin Gjevori, E. (2018), "Understanding intellectual capital disclosure in online media big data: an exploratory case study in a university", Meditari Accountancy Research.

Paklina, S., Molodchik, M. and Parshakov, P. (2018), "Digital relational capital of a company", Meditari Accountancy Research. 
MEDAR

26,3

\section{0}

Romanelli, M. (2018), "Museums creating value and developing intellectual capital by technology: from virtual environments to big data", Meditari Accountancy Research.

Secundo, G., Del Vecchio, P., Dumay, J. and Passiante, G. (2017), "Intellectual capital in the age of big data: establishing a research agenda”, Journal of Intellectual Capital, Vol. 18 No. 2, pp. 242-261.

Uden, L. and Del Vecchio, P. (2018), “Transforming the stakeholders' big data for intellectual capital management", Meditari Accountancy Research.

\title{
Further reading
}

Laney, D. (2001), “3-D data management: controlling data volume, velocity and variety", Application Delivery Strategies by META Group Inc. (2001, February 6), p. 949, available at: http://blogs.gartner.com/doug-laney/files/2012/01/ad949-3D-Data-Management-ControllingData-Volume-Velocity-and-Variety.pdf

\begin{abstract}
About the authors
Giustina Secundo is a Senior Researcher in Management Engineering at University of Salento (Italy). Her research is characterised by a cross-disciplinary focus, with a major interest toward knowledge assets management, innovation management and knowledge-intensive entrepreneurship. Her research activities have been documented in about 150 international papers. Her research appeared in Technovation, Technological Forecasting \& Social Change, Journal of Business Research, Journal of Intellectual Capital, Knowledge Management Research \& Practices, Measuring Business Excellence and Journal of Knowledge Management. She is a Lecturer of Project Management at the Faculty of Engineering of the University of Salento since 2001. She is a member of the Project Management Institute. Across 2014 and 2015, she has been visiting researcher at the Innovation Insights Hub, University of the Arts London (UK).

John Dumay is an Associate Professor in Accounting at Macquarie University, Sydney. Originally a consultant, he joined academia after completing his award-winning $\mathrm{PhD}$ in 2008. John's research specialties are intellectual capital, knowledge management, non-financial reporting, management control, research methodologies and academic writing. John has published over 50 peer-reviewed articles in leading academic journals. He is also on the Editorial Board of Advice of eight accounting journals, including the Accounting, Auditing and Accountability Journal, is the Australasian Editor of the Journal of Intellectual Capital and serves as Editor of the Electronic Journal of Knowledge Management.

Pasquale Del Vecchio, $\mathrm{PhD}$, is a Researcher and Lecturer at the Department of Engineering for Innovation of the University of Salento, Italy. In 2007, he was a visiting PhD student at the Center for Business Intelligence at MIT's Sloan School of Management where he had the opportunity to consolidate the methodological framework of his thesis titled "CRM 2.0 and Reputational Dynamics in the Blogosphere. Lessons learnt from a Software Firm Case Study". His research field concerns the issues of user-driven innovation and open innovation with a specific focus on the phenomenon of virtual communities of customers. Currently, he is involved in a project related to the development of a model for the smart specialisation of a regional destination as well as in development of innovative approaches at the creation of technology-driven entrepreneurship. These research activities have been documented in approximately 40 publications spanning international journals, conference proceedings and book chapters.
\end{abstract}

